\title{
Beginning L2 complexity development in CLIL and non-CLIL secondary education
}

\author{
Bram Bulté and Alex Housen
}

\begin{abstract}
The present study analyses the impact of a bilingual Content and Language Integrated Learning (CLIL) programme vis-à-vis a regular monolingual programme on the development of different aspects of L2 learners' linguistic (syntactic, morphological and lexical) complexity. Five pupils enrolled in a Dutch-English CLIL programme in a secondary school in the Netherlands are compared with five peers following the mainstream programme with English as a Foreign Language (EFL) teaching. The longitudinal development of these ten pupils' linguistic complexity in L2-English is investigated by means of six complexity measures calculated for each of eleven writing tasks collected over a period spanning their first nineteen months of secondary education. Linear mixed models are used to estimate the effects of time and programme type on the pupils' L2 complexity. The results indicate that both groups of learners significantly increase the complexity of their L2 writing over the course of the study. Surprisingly, only limited effects of programme type (CLIL vs non-CLIL) are found, despite considerable differences in the quantity and quality of instructional exposure to the target language, suggesting that for these pupils increased and more varied instructional exposure to the L2 in the CLIL programme did not lead to significantly different L2 productions in terms of linguistic complexity.
\end{abstract}

\section{Affiliations}

Bram Bulté: Vrije Universiteit Brussel, Belgium email: bram.bulte@vub.be

Alex Housen: Vrije Universiteit Brussel, Belgium email: alex.housen@vub.be 
Several possible explanations for these findings are considered and the implications for CLIL research are discussed.

KEYWORDS: SYNTACTIC; MORPHOLOGICAL AND LEXICAL COMPLEXITY; L2 WRITING; LONGITUDINAL DEVELOPMENT; BILINGUAL EDUCATION; CLIL

\section{Introduction}

Bilingual education programmes such as Content and Language Integrated Learning (CLIL) and immersion are burgeoning in Europe on the assumption that they significantly promote second language ${ }^{1}$ (L2) learning without negatively affecting pupils' first language (L1) proficiency or content learning (Dalton-Puffer 2011). However, many of the purported benefits of these programmes still await empirical confirmation (Bruton 2013; PérezCañado 2012). Few effectiveness studies track development longitudinally and empirical evidence for this assumption is still scant, particularly as far as the linguistic component of L2 proficiency is concerned (Lázaro and García Mayo 2012; Martínez Adrián and Gutiérrez Mangado 2015a, b).

The study reported in this paper aims to address these gaps by longitudinally examining the linguistic development in the L2 (English) of a small sample of Dutch-speaking children enrolled in an English CLIL programme in a secondary school in the Netherlands, and comparing their development over a nineteen-month period (spanning the first two school years) with that of matched peers enrolled in a mainstream programme with traditional English as a Foreign Language (EFL) lessons. ${ }^{2}$ The study focuses on the pupils' linguistic complexity (i.e. syntactic, morphological and lexical complexity), one of the principal components or basic dimensions of linguistic proficiency, along with accuracy and fluency (Housen and Kuiken 2009), but one which has received little attention in studies of the relative effectiveness of CLIL programmes.

This paper is structured as follows. First, we outline the principles and design features of CLIL and how CLIL education compares to mainstream education with traditional Foreign Language (FL) education. We also review the available research on the relative efficacy of CLIL education for developing L2 proficiency. The next section focuses on the implementation and results of CLIL in the specific context of the Netherlands. This is followed by a discussion of the construct of L2 complexity and an overview of research findings on L2 complexity development in CLIL contexts. After stating the research questions, the methodology section describes the participants, data, complexity measures and statistical procedures of the study. Results are presented next, followed by the discussion and conclusion. 


\section{Content and Language Integrated Learning (CLIL)}

CLIL shares with other forms of bilingual education (such as immersion) the teaching of non-language content in a language other than the official school language. Although the overriding focus in CLIL classrooms is on meaning and content, its distinctive feature is the dual and integrated focus on both language and content learning goals (Coyle, Hood and Marsh 2010). The primary motivation for implementing CLIL is to enhance pupils' language skills in the CLIL target language while attaining the same level of content knowledge and L1 competence that would have been achieved if the content taught in the CLIL language had been taught in the school's official language of instruction. Interpretations, applications and concrete practices of CLIL vary considerably, both across and within countries and regions, and often even within individual programmes and schools (Cenoz, Genesee and Gorter 2014; Dalton-Puffer, Nikula and Smit 2010).

CLIL is believed to provide an acquisition-rich environment which differs considerably from that of mainstream FL teaching (Lorenzo, Moore and Casal 2011). CLIL can offer increasingly varied exposure to a wider range of language structures and a broader range of language usage situations than is usually afforded by the traditional FL classroom. CLIL is also able to crucially differ in terms of the employment of such learning mechanisms as attention and awareness allocation (Schmidt 1990), subject content processing strategies (deep processing), as well as in terms of the learning of linguistic constructions and procedures (Tomasello 2003).

The outcomes of CLIL education, and its effectiveness compared to mainstream education with conventional FL teaching, are shrouded in controversy (Bruton 2017; Cenoz, Genesee and Gorter 2014; Pérez-Cañado 2017). Many publications state but far fewer convincingly demonstrate the effectiveness and beneficial outcomes of CLIL (Bruton 2011, 2013; PérezCañado 2017; for reviews of CLIL research, see Cenoz, Genesee and Gorter 2014; Dalton-Puffer 2017; Pérez-Cañado 2012).

A number of trends can be distilled from a careful reading of the varied CLIL research literature. Most (though not all) studies report significantly higher target language levels for CLIL pupils than for pupils in mainstream education. CLIL pupils in particular outperform non-CLIL pupils in terms of general communicative competence, receptive skills (reading and listening comprehension), speaking fluency (both in terms of speech rate and amount of language produced), morphology (higher automatisation and appropriacy of use), and breadth of vocabulary (particularly technical and semi-technical terms). Beneficial effects of CLIL have also been reported in other language-related aspects of behaviour, such as creativity,

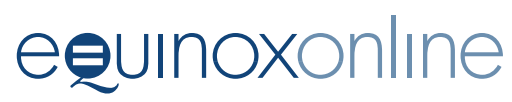


risk-taking and emotive/affective outcomes (e.g. learner motivation and language anxiety). However, no or at best indeterminate effects of CLIL have been found for pronunciation (accuracy, accent), syntax (accuracy, appropriateness and sophistication), and general (informal and nontechnical) vocabulary and pragmatics. The lack of effects of CLIL in these language domains has been ascribed to an insufficient focus on form in CLIL classrooms (Pérez-Cañado 2012).

Several important caveats have to be kept in mind when interpreting the results of studies investigating the effects of CLIL on language outcomes. First, many studies on the effectiveness of CLIL are methodologically flawed: 'Many CLIL studies are stand-alone qualitative pieces and what quantitative investigation there is rarely guarantees the homogeneity of the treatment and comparison groups, factors in moderating variables, or performs statistical analyses to determine whether the gains observed are truly ascribable to CLIL practice' (Pérez-Cañado 2012:330). Second, few CLIL effectiveness studies have been longitudinal in nature. Longitudinal studies are necessary to determine not only whether CLIL pupils show higher final outcome levels - which may also be due to their initial head start as a result of the selective nature of many CLIL programmes, which attract or are admissible only to highly motivated and/or linguistically more gifted pupils (cf. Bruton 2011; Dalton-Puffer 2017) - but also whether CLIL pupils make more language gains and faster progress over time than non-CLIL pupils. Third, so far, language outcomes of CLIL have been mainly assessed by means of global procedures that measure pupils' general communicative skills and language proficiency (e.g. holistic ratings, standardised tests of the four basic skills), but not the various components and dimensions that make up language proficiency, such as complexity, accuracy and fluency (Dalton-Puffer 2017).

The present study seeks to address several of the above limitations of current CLIL research by focusing on the longitudinal development of the complexity dimension of the linguistic proficiency of CLIL vs non-CLIL pupils in the specific context of the Netherlands.

\section{CLIL in the Netherlands}

Bilingual programmes have been organised in the Netherlands for nearly thirty years now, and there is a rich tradition of research focusing on different aspects of their implementation and effects. Bilingual programmes exist in primary, secondary and tertiary education, and are highly institutionalised and monitored (see e.g. Jenniskens et al. 2018; Verspoor et al. 2010). A number of factors are important for a correct understanding of 
the effects and effectiveness of CLIL in the Netherlands. The first is that several Dutch CLIL programmes not only offer variable and often substantial amounts of subject matter teaching through the CLIL language (which is almost always English), but they may also offer more EFL teaching than in regular non-CLIL programmes (as in the specific CLIL programme under investigation in this study). Second, the total amount of time taught through English (CLIL lessons plus EFL lessons) in Dutch CLIL programmes is often in excess of $50 \%$ of total teaching time, which is considerably more than in many CLIL programmes in other European countries or regions (e.g. Flanders, Spain). Third, Dutch pupils are typically exposed to a considerable amount of contact with English outside school, mainly through audiovisual media (internet, radio, television/film, where English programmes are typically subtitled rather than dubbed). Given the prominence of English in Dutch society, some have argued that English is a second rather than a foreign language in the Netherlands, even though it has no official status in the country's government or administration (Edwards 2014). A final factor to be kept in mind when comparing the results of CLIL programmes in the Netherlands with those in other national contexts is the fact that English and Dutch are closely related, with many lexical and grammatical (near) cognates, which facilitates comprehension and learning (see Lindgren and Muñoz 2013, who found that typological proximity between the L1 and L2 and out-of-school language contact were the two most important predictors of L2-English proficiency differences between European countries).

In the remainder of this section, we review two empirical studies that are of particular relevance for our study, since they focus on the effects of CLIL on L2-English proficiency in the secondary (rather than primary or tertiary) school context.

Admiraal, Westhoff and de Bot (2006) conducted a longitudinal study of pupils in five Dutch secondary schools who received four years of CLIL education, and who were compared with pupils in a regular programme with only EFL teaching. A total of 1305 pupils were tested for receptive vocabulary knowledge, reading comprehension and oral proficiency in the L2, with gender, entry ability level, home language, language contact outside school and motivation as covariates. The CLIL pupils were found to outperform the non-CLIL pupils on the oral and reading measures, but no differences were observed for receptive word knowledge. The CLIL and non-CLIL pupils obtained comparable levels of L1 and subject matter achievement. Given the typically selective nature of CLIL education in the Netherlands, the CLIL and non-CLIL groups in this study were not entirely matched and, as the authors themselves admit, the statistical analyses used 
did not allow the results obtained to be unambiguously attributed to the CLIL teaching practices (Admiraal, Westhoff and de Bot 2006:91).

More recently, Verspoor and colleagues (2015) studied the impact of a CLIL programme on the L2-English proficiency of pupils enrolled in the first and third year of four Dutch secondary schools. They explicitly address issues raised by Bruton (2011) in his criticism of current CLIL research, for example by taking into account initial L2 proficiency levels and the problem of the selectivity of CLIL programmes. The development of the scores of 399 pupils on a receptive vocabulary test and holistic ratings of an informal writing task over a one-year period were analysed, while controlling for the pupils' scholastic aptitude, initial English proficiency, outof-school contact and motivation. The results lead the authors to conclude 'that bilingual education has had a positive effect on the development of English proficiency in our learners, but that other factors such as scholastic aptitude and initial proficiency also play a strong role' (Verspoor, de Bot and Xu 2015:23). Moreover, they emphasise the dynamic and variable nature of L2 development in general, which is shaped by the complex interplay of different factors (and not only CLIL instruction as such).

The two studies reviewed above, as indeed most empirical CLIL studies so far, used purpose-built general proficiency tests and holistic ratings to quantify L2 development. In an attempt to identify aspects of language whose development may be more or less susceptible to CLIL instruction, a few studies have looked at more specific aspects or more narrowly defined subdomains of linguistic L2 proficiency, such as verb morphology and word order (Lázaro and García Mayo 2012; Martínez Adrián and Gutiérrez Mangado 2015a, b) or linguistic complexity, which is the focus of investigation in our study.

\section{L2 complexity and its measurement}

Complexity has been posited as a major dimension of L2 performance, L2 proficiency and L2 development, typically alongside such other basic dimensions as accuracy and fluency (Bulté and Housen 2012; Housen and Kuiken 2009). Complexity commonly refers to the use of a wide and varied range of (sophisticated or structurally elaborated) linguistic (lexical, syntactic, morphological) structures and elements in the L2.

In L2 research, complexity has been measured either subjectively, through rating scales, or, more commonly, through the use of objective quantitative measures. Early studies on L2 complexity used only a handful of global syntactic and lexical complexity measures that targeted the structural elaboration and diversity of the syntactic and lexical systems to

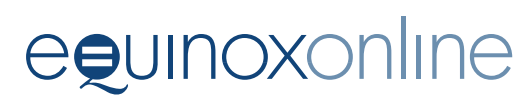


compare (mostly written) language samples collected from learners at different proficiency levels or stages of development (for overviews, see Bulté and Housen 2012; Ortega 2003; Wolfe-Quintero, Inagaki and Kim 1998). Higher values of several of these measures, such as mean length of sentence or T-unit, subordinate clause ratios or lexical type-token ratios, were found to be associated with higher proficiency and more advanced stages of development (Ortega 2003; Wolfe-Quintero, Inagaki and Kim 1998). As L2 complexity research evolved and with the advance of automated complexity and natural language processing (NLP) tools (see e.g. Kyle 2016), the repertoire of complexity measures has proliferated to include hitherto unexplored language domains (e.g. morphological complexity; Brezina and Pallotti 2019; De Clercq and Housen 2019).

Such recent advances notwithstanding, empirical research on L2 complexity has produced many inconsistent findings (see reviews in Bulté and Housen 2012; Norris and Ortega 2009). This, in combination with the growing attention to L2 complexity as a primary focus of research (instead of merely as a dependent variable), has prompted researchers to take a more critical look at L2 complexity as a construct and as a research variable (Bulté and Housen 2012; Norris and Ortega 2009). Researchers such as Pallotti (2015) have called for a simpler approach to defining and operationalising L2 complexity, in order to avoid the terminological confusion and circular reasoning that characterises much L2 complexity research (Bulté and Housen 2014). In response to this call, complexity in our study is defined as absolute, structural complexity, independent of considerations about the cognitive complexity (or difficulty) of certain linguistic features, or about when they are acquired or emerge in L2 development (Bulté and Housen 2012). Absolute structural complexity is an essentially quantitative notion (Rescher 1998), reflected by the number of phonemic, lexical, morphological or syntactic items, structures or rules manifested in a language sample or in the language user's linguistic repertoire.

The next section discusses the few published studies that have investigated linguistic complexity in CLIL contexts.

\section{CLIL effects on complexity in L2 writing}

In this section, we briefly discuss studies that investigate the impact of CLIL on linguistic complexity in L2 writing performance in a secondary school context. We are not aware of any studies that gauge the effects of CLIL on L2 complexity in a Dutch context. Therefore, we discuss four published studies that look explicitly at CLIL effects on L2 writing complexity in other European contexts (francophone Belgium, Catalonia and Asturias).

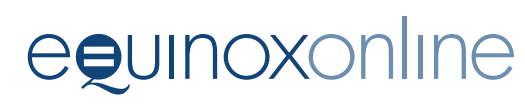


Bulon and co-workers (2017) studied the syntactic and lexical complexity of the L2-English and L2-Dutch writings of a group of 438 pupils aged 15-19 in French-speaking Belgium, comparing CLIL and non-CLIL programmes in a cross-sectional design. Participants were asked to write an informal email under timed conditions. The study provides no background information about the CLIL programme in question (starting age, number of CLIL and FL hours, course topics). The CLIL pupils significantly outperformed the non-CLIL pupils for L2-Dutch writing in terms of total number of sentences and words, mean length of sentence, average word length and lexical diversity (as measured by the measure of textual lexical diversity, MTLD; McCarthy and Jarvis 2010). For L2-English writing, the CLIL pupils scored higher than the non-CLIL pupils in terms of sentences per texts and MTLD, but not in terms of mean sentence length, average word length or lexical type-token ratio (TTR).

Gené-Gil and associates (2015) investigated differences in the longitudinal development of complexity, accuracy and fluency (CAF) in the L2-English writings of fifty bilingual Spanish/Catalan pupils, aged 13-16. One group followed a CLIL programme, the other a regular curriculum with traditional EFL instruction. Data collection spanned three years and began at the start of the CLIL programme. Both groups received around 105 hours of EFL per year, and the CLIL group had an additional 105 hours of content classes (science or social science) in English. On four occasions, participants were given twenty-five minutes to write an email to a friend about a film they had recently watched. The non-CLIL group only progressed significantly in terms of lexical diversity (as measured by $D$; Malvern et al. 2004). The CLIL group made significant progress in terms of both syntactic complexity (as measured by the proportion of subordinate clauses and the co-ordination index; Bardovi-Harlig 1992) and lexical diversity.

Pérez-Vidal and Roquet (2015) conducted a pre-test-post-test study with 13/14-year-old Catalan/Spanish bilingual learners of English $(n=100)$, half of whom were enrolled in a CLIL programme. At the time of the pretest, the CLIL group was in the first year of secondary education, and had received 1120 hours of EFL instruction plus 210 hours of CLIL (science) classes. The non-CLIL group was in the second year of secondary education, and had received 1260 hours of EFL instruction. Between the pre-test and the post-test, the CLIL group received 70 hours of CLIL classes and 140 hours of EFL instruction, compared to 140 hours of EFL instruction for the non-CLIL group. The participants were asked to write a dialogue they imagined upon seeing a picture of a scene, as well as a description of what might have happened before the depicted scene and what could happen

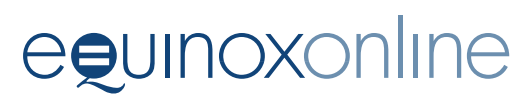


next. Analyses of the L2 writings revealed that the CLIL group increasingly relied on subordination as a means of clause linking over the course of the study (as measured by the co-ordination index), whereas for the non-CLIL group the opposite was the case, with an increased reliance on co-ordination. In contrast, both groups scored higher in terms of lexical diversity on the post-test than on the pre-test (as measured by the Guiraud index), but the non-CLIL group recorded higher relative gains. Note that no statistical tests were performed to test whether these differences were significant.

Lahuerta Martínez (2015) compared nearly 400 CLIL and non-CLIL pupils in Asturias, Spain, enrolled in the third and fourth year of secondary education. Even though they had started learning English at five years of age, they were only estimated to be at the A1-A2 level of the Common European Framework of Reference for Languages (CEFR) at the onset of the study. The CLIL students had been enrolled in a CLIL programme since their primary education, and had been exposed to a total of 972 hours of teaching in and on English in primary school, in addition to five hours of EFL classes and three hours of CLIL classes in secondary school. The nonCLIL group had received 540 hours of EFL classes in their primary education, and had either four (Years 1-3) or three (Year 4) hours of EFL classes in their secondary education. All participants were given thirty minutes to write an argumentative essay. The study reported higher writing complexity scores in L2-English for the CLIL group in terms of words per sentence and lexical diversity (as measured by the root TTR), but not in terms of sentence complexity (somewhat confusingly measured as 'sentences per clause').

To summarise, as often occurs in the empirical CLIL literature, the picture that emerges from these four studies is a mixed one. It must be noted that the available empirical studies into CLIL effects on L2 complexity development in secondary education have been either cross-sectional or are only quasi-longitudinal at best. Most also do not include a true pre-test, i.e. data collected at the onset of the CLIL programme. Not surprisingly therefore perhaps, no clear pattern emerges from the available studies: sometimes the CLIL group outperforms the non-CLIL group in terms of syntactic and/or lexical complexity (morphological complexity not having been investigated), but this pattern is not consistent across all studies and, again, when an advantage for CLIL pupils is found, this cannot unequivocally be attributed to the CLIL component.

Moreover, in interpreting these results it should be kept in mind that there are considerable differences between the CLIL programmes in the studies reviewed here and the Dutch CLIL programme in our study, in terms of the amount of time devoted to CLIL in the curricula, the specific 
pedagogical and didactic approaches used, the amount and nature of out-of-class exposure to the CLIL language, and the typological distance between the pupils' L1s and the L2 (in the studies reviewed here, the pupils spoke a Romance first language and learned a Germanic second language). These last two factors have been shown to have a substantial impact on L2 learning and L2 accuracy, fluency and complexity development in other forms of bilingual education (Lindgren and Muñoz 2013; Housen 2012; Housen et al. 2011). It is legitimate to ask, then, whether English CLIL education has a different impact on linguistic complexity development in the context of secondary education in the Netherlands compared with the contexts investigated in previous studies.

In the next section, we present the research questions and the methodology of our empirical study, starting with the participants and research context. Next, we provide an overview of the data elicitation and processing procedures. Finally, the data analysis procedures are described.

\section{Research questions and methodology}

\section{Research questions}

The following two research questions guided our empirical study:

1 How and how much does the syntactic, lexical and morphological complexity of the second language writing of Dutch-speaking learners of English in a bilingual CLIL programme and in a mainstream foreign language programme in the Netherlands increase over the first nineteen months of secondary education?

2 Are there differences in the rate and amount of L2 complexity development between the pupils in the two instructional contexts?

We addressed these questions by means of an exploratory study with a longitudinal multiple case-study design.

\section{Participants and research context}

Five pupils (aged 11-13) enrolled in the first year of a bilingual DutchEnglish CLIL programme in a secondary school in the north of the Netherlands were compared to five pupils in the same school following a regular monolingual Dutch programme with a traditional EFL curriculum. This homogeneous sample of learners was selected from a larger corpus (Verspoor, de Bot and Xu 2015; Verspoor, Schmid and Xu 2012), ensuring comparability in terms of factors such as language background (L1 
$=$ Dutch), socioeconomic variables and overall school performance (all scored high to very high, i.e. 544/550 or more, on the Dutch Cito test, the central nationwide test of scholastic aptitude; see Verspoor, de Bot and Xu 2015). At the start of their secondary school career, all ten pupils in this study were at the A2-B1 level of the CEFR scale with no statistically significant difference between the CLIL and non-CLIL pupils. A background questionnaire revealed that the pupils in this study had one or two years of prior EFL experience in primary school. ${ }^{3}$ In addition, before and during the time of the study the CLIL and non-CLIL pupils (had) had comparable, and substantial, amounts of contact with English outside the school context, mainly through audiovisual media (radio, television; Verspoor et al. 2010).

In the bilingual programme under investigation, CLIL in English starts in the first year of secondary school. Half of the curriculum (fifteen fiftyminute lessons each week) is taught in English, including five lessons of EFL subject teaching plus ten general content lessons in the CLIL language (e.g. mathematics, art, biology). Pupils in the CLIL programme thus receive a total of approximately 600 lessons (or 500 hours) per year in English. In the monolingual Dutch programme, pupils receive two EFL lessons per week (or approximately eighty lessons or sixty-seven hours per year in English). This means that over the course of the nineteen-month study, the CLIL group received approximately 975 hours of instruction in or about English, and the non-CLIL group 130 hours. The CLIL content teachers in this programme are L2 speakers with at least a B2 level of proficiency for each of the four major language skills according to the CEFR. Teachers use English almost exclusively in the classroom and insist on pupils speaking only English during the lessons taught in English. Only authentic English materials are used. This CLIL programme, then, is an example of what Dalton-Puffer (2017) calls 'hard CLIL', whereby the primary goal of the CLIL lessons is to teach and learn general (i.e. non-language) subject matter, but instances of form-focused language instruction (Spada 1997) are provided when the need arises to promote the acquisition and mastery of the CLIL language. Systematic focus-on-form and focus-on-forms instruction (Long 1991) is provided during the EFL subject lessons.

\section{Data and data elicitation}

The data set consists of eleven written texts produced by each of the ten learners over a period of nineteen months (October 2007-May 2009) at varying time intervals. Each learner completed the same eleven informal writing tasks, and did so at the same points in time, yielding a balanced corpus. The texts, ranging in length from 30 to 210 words, were written 
Table 1: Writing prompts and timing of the tasks.

\begin{tabular}{|c|c|c|}
\hline$\#$ & Time & Prompt \\
\hline 1 & 1 October 2007 & Write a short story about your new school, friends and teachers. \\
\hline 2 & 30 October 2007 & Write a short story about your favourite pet animal. \\
\hline 3 & 27 November 2007 & Saint Nicholas. \\
\hline 4 & 18 December 2007 & What will you do for Christmas? \\
\hline 5 & 1 February 2008 & $\begin{array}{l}\text { Pretend you have a foreign pen-pal. Tell him/her about your } \\
\text { favourite holiday and explain what you find so special about it. }\end{array}$ \\
\hline 6 & 1 June 2008 & $\begin{array}{l}\text { The most awful (or best) thing that happened to you at school so } \\
\text { far. It does not have to be truthful. }\end{array}$ \\
\hline 7 & 1 October 2008 & $\begin{array}{l}\text { The most awful (or best) thing that happened to you during } \\
\text { summer vacation. It does not have to be truthful. }\end{array}$ \\
\hline 8 & 4 January 2009 & Write about the rules at home. Do you think they are fair or not? \\
\hline 9 & 1 February 2009 & $\begin{array}{l}\text { Pretend you have just won } 1000 \text { euros. Write a short story about } \\
\text { what you would do with the money. }\end{array}$ \\
\hline 10 & 1 March 2009 & $\begin{array}{l}\text { Write about someone you really admire (actor, singer, sportsman, } \\
\text { teacher, politician, etc.). Why? }\end{array}$ \\
\hline 11 & 1 May 2009 & $\begin{array}{l}\text { What would you like to be when you grow up/what kind of job } \\
\text { would you like to have? }\end{array}$ \\
\hline
\end{tabular}

on the computer (without any reference tools such as spelling or grammar checkers activated) in a dedicated classroom. No time limit was imposed to complete the tasks. The eleven writing prompts as well as the dates on which the writing tasks were completed are presented in Table 1 . The conditions under which each text was written were identical, and also the characteristics of the tasks were highly comparable (Robinson 2007), although the eleven prompts were not identical in nature, eliciting texts that represent slightly different (sub-)genres or text types, including predominantly argumentative, descriptive and narrative texts, and combinations thereof. More information about the data set analysed in this study can be found in Bulté (2013).

\section{Data processing}

The learners' texts were transcribed in CHAT Format (MacWhinney 2000) and segmented into clauses. Spelling errors were corrected to allow for lexical analyses to be performed. Some of the analyses were performed with automated tools such as CLAN Software (MacWhinney 2000) and Range Software (Heatley et al. 2002). The coding of syntactic units (T-units, main and subclauses, noun phrases) was done manually following the operational definitions of each unit proposed by Bulté (2013). ${ }^{4}$ 


\section{Data analysis - complexity measures}

We used five complexity measures, targeting lexical (1), syntactic (3) and morphological (1) complexity, as well as an aggregated measure combining the scores from these five individual measures (see Table 2). The three syntactic measures target three different aspects of syntax: length of sentential unit (mean length of T-unit; MLTU), extent of clause combining by means of subordination (subclause ratio; SCR), and phrasal elaboration (mean length of noun phrase; MLNP). MLTU and SCR are among the most popular syntactic complexity measures in L2 writing studies (Bulté and Housen 2012). MLNP is included in accordance with calls to look beyond the supra-clausal level (Norris and Ortega 2009).

Lexical complexity was measured by means of the Guiraud index, $G$, a transformation of the type-token ratio that compensates for the effects of text length (Guiraud 1959). This measure is considered a metric of the lexical diversity (i.e. size, richness, variety) of L2 production (Jarvis 2013). It is preferred here over more exact mathematical transformations that remove the effect of text length on lexical TTRs (see e.g. McCarthy and Jarvis 2010), since the square root in the denominator actually overcompensates for text length, yielding higher scores for longer texts (Bulté et al. 2008). This is in line with the characterisation of lexical diversity proposed by Jarvis (2013) and with the definition of complexity adhered to in this study. Furthermore, since function words arguably have more to do with grammar than with vocabulary (the mental lexicon), we only include content words in the analysis of lexical complexity (Bulté et al. 2008).

The morphological complexity measure, $V F$, targets the diversity of inflectional verb morphology. Although grammatical morphology represents a major learning challenge for most L2 learners, morphological complexity has not been frequently measured in L2 complexity research (however, see Brezina and Pallotti 2019; De Clercq and Housen 2019),

Table 2: Quantitative complexity measures.

\begin{tabular}{ll}
\hline Measure & Formula \\
\hline Syntactic complexity & \\
Mean length of T-unit (MLTU) & $n$ T-units / $n$ tokens \\
Subclause ratio (SCR) & $n$ subclauses / $n$ clauses \\
Mean length of noun phrase (MLNP) & $n$ tokens in NPs / $n$ NPs \\
\hline Lexical complexity & $n$ types / $\sqrt{ }$ ( $n$ tokens) \\
Guiraud index (G) & $n$ verb forms $+n$ forms of 'to be' \\
\hline Morphological complexity & \\
\hline Number of verb forms (VF)
\end{tabular}


in contrast to typological linguistic research where it has been the main focus of attention (Baerman, Brown and Corbett 2015). The morphological complexity measure used here consists of a count of the total number of different inflectional categories of lexical verbs (i.e. stem, third person singular, present participle, preterit and past participle) plus the inflectional categories of the verb 'to be' occurring in a text. The maximum score that can be obtained on this measure is 13 (Bulté 2013).

In order to combine the scores from these five measures into a single aggregate measure, standardised scores were calculated for each individual measure and summed. The advantage of this method is that the measures to be included as well as their relative weight can be determined independently from the collected data. No weighting of measures was applied.

\section{Statistical modelling and inference}

Since we were mainly interested in comparing overall trends between two groups of learners (in terms of rate and amount of development), we fitted linear models to the data. It could be argued that such models do not do full justice to the irregular patterns that may characterise the L2 complexity development of individual learners (Bulté and Housen 2018), but we believe that linear models offer a number of advantages for answering our research questions: parameter estimates reflecting group differences are easily comparable, potential differences between groups are straightforward to interpret, and the structure and interpretation of the models is identical for different outcome measures.

We used mixed-effects or multilevel models, accounting for the fact that the repeated observations within subjects are potentially correlated. Since the data collection points are unequally spaced, a General Linear Mixed-effects Model was preferred over multivariate regression (Verbeke and Molenberghs 2000). A dichotomous variable representing educational context ('CLIL' and 'non-CLIL/mainstream') was included as a fixed effect to model the differences in instructional L2 contact between the two groups of participants. The interaction term between educational context and time was also added to the model, in order to allow for different time effects for both groups. Random coefficients were restricted to random intercepts (assuming constant variance). We used the MIXED Procedure in SAS to fit the model to the data. Parameters were estimated using restricted maximum likelihood estimation. With the CONTRAST Statement we performed approximate $F$-tests to determine whether the overall effect of 'time' was significant, and whether it significantly differed between both groups of learners. We used the LSMEANS Procedure to 
estimate whether the difference between (the least squares means of the) CLIL and non-CLIL pupils was significant or not.

\section{Results}

As a general point of reference, Table 3 shows the descriptive statistics (means, with standard deviations in parentheses) for all measures for both groups (with 5 times 11 texts each). A complete overview of descriptive statistics per time point (1-11) and group (CLIL vs non-CLIL) is provided in Appendix 1.

In response to our two main research questions, Table 4 provides an overview of the fixed and random parameter estimates for the mixed models per outcome measure, as well as the statistical inference for the marginal model (approximate $F$-tests and significance of least squares means differences). The intercepts show the estimated scores at the onset of the study for each group, whereas the time effects indicate how much estimated change there is in the outcome measure per unit of time (i.e. one month) for each of the groups. For example, the intercept for the CLIL group for MLTU is 7.44 and the time effect is 0.14 , which means that for the second task (i.e. after one month) the expected score is 7.58. By the end of the study (i.e. after nineteen months), the expected MLTU for this group is 10.10 .

To discuss each of the six measures in turn, there is, first, a small difference in MLTU between both groups at the onset of the study (CLIL - 7.44; non-CLIL - 7.11). The scores for both groups increase in parallel over the course of the study $(+0.14$ per month). The increase over time is significant but the mean difference between both groups is not, nor is the difference in their rate of change over time. In the case of the SCR measure, the CLIL group also starts at a higher point (0.19) than the non-CLIL group (0.13). The rate of increase over time, which overall is significant, is slightly higher for the former than for the latter $(0.013 \mathrm{vs} 0.011)$, but this difference is not significant. The overall difference in means between both groups is also not significant.

Table 3: Descriptive statistics.

\begin{tabular}{lcccccc}
\hline & MLTU & SCR & MLNP & G & VF & Combined \\
\hline CLIL $(n=55)$ & 8.67 & 0.30 & 2.55 & 4.78 & 5.40 & 0.31 \\
& $(2.13)$ & $(0.16)$ & $(0.42)$ & $(1.02)$ & $(1.79)$ & $(3.18)$ \\
Non-CLIL $(n=55)$ & 8.31 & 0.22 & 2.71 & 4.70 & 5.05 & -0.30 \\
& $(1.49)$ & $(0.15)$ & $(0.54)$ & $(0.96)$ & $(1.59)$ & $(2.94)$ \\
\hline
\end{tabular}


Table 4: Parameter estimates for mixed models and statistical inference for marginal model.

\begin{tabular}{lcccccc}
\hline & MLTU & SCR & MLNP & G & VF & Combined \\
\hline Fixed effects & & & & & & \\
Intercepts & & & & & & \\
CLIL & 7.44 & 0.19 & 2.36 & 4.05 & 4.70 & -2.59 \\
& $(0.49)$ & $(0.04)$ & $(0.11)$ & $(0.26)$ & $(0.34)$ & $(0.69)$ \\
Non-CLIL & 7.11 & 0.13 & 2.37 & 4.27 & 4.50 & -2.93 \\
& $(0.49)$ & $(0.04)$ & $(0.11)$ & $(0.26)$ & $(0.34)$ & $(0.69)$ \\
Time effects & & & & & & \\
CLIL & 0.14 & 0.013 & 0.02 & 0.08 & 0.08 & 0.33 \\
& $(0.03)$ & $(0.002)$ & $(0.008)$ & $(0.02)$ & $(0.03)$ & $(0.04)$ \\
Non-CLIL & 0.14 & 0.011 & 0.04 & 0.05 & 0.06 & 0.30 \\
& $(0.03)$ & $(0.002)$ & $(0.008)$ & $(0.02)$ & $(0.03)$ & $(0.04)$ \\
Variance components & & & & & & \\
Learner & 0.76 & 0.003 & 0.018 & 0.18 & 0.00 & 1.53 \\
& $(0.47)$ & $(0.002)$ & $(0.017)$ & $(0.12)$ & & $(0.92)$ \\
Residual & 1.88 & 0.015 & 0.178 & 0.63 & 2.67 & 3.41 \\
& $(0.27)$ & $(0.002)$ & $(0.025)$ & $(0.09)$ & $(0.37)$ & $(0.49)$ \\
VPC & $28.8 \%$ & $14.8 \%$ & $9.4 \%$ & $22.1 \%$ & - & $31.0 \%$ \\
REML log likelihood & 405.2 & -113.0 & 147.5 & 286.1 & 428.7 & 468.9 \\
LS means difference & & & & & & \\
CLIL vs non-CLIL & & & & & & \\
$\quad$ Difference & -0.36 & -0.08 & 0.16 & -0.08 & -0.35 & -0.61 \\
$\quad$-value & $(0.61)$ & $(0.04)$ & $(0.12)$ & $(0.31)$ & $(0.31)$ & $(0.86)$ \\
Contrasts & -0.59 & -1.92 & 1.33 & -0.25 & -1.11 & -0.71 \\
CLIL effect & & & & & & \\
$\quad$ F (df = 1,98) & 0.01 & 0.28 & 1.99 & 2.41 & 0.15 & 0.36 \\
$\quad$ Time effect & & & & & & \\
F df = 2, 98) & $52.20^{* *}$ & $24.61^{* *}$ & $14.00^{* *}$ & $19.18^{* *}$ & $5.03^{*}$ & $75.55^{* *}$ \\
\hline
\end{tabular}

Note: estimates with standard error in parentheses; ${ }^{*} p<0.01$; ${ }^{* *} p<0.001$; VPC, variance partitioning coefficient; REML, restricted maximum likelihood; LS, least squares; df, degrees of freedom.

For MLNP, both groups start at around the same level (CLIL - 2.36; non-CLIL - 2.37), and the increase in the non-CLIL group (0.04) is steeper than in the CLIL group (0.02), but not significantly so. The overall effect of time is significant, however. On average, there is no significant difference between both groups. When we look at the measure of lexical diversity, the non-CLIL group starts higher (4.27) than the CLIL group (4.05), but the rate of increase is higher in the CLIL (0.08) than in the non-CLIL group 


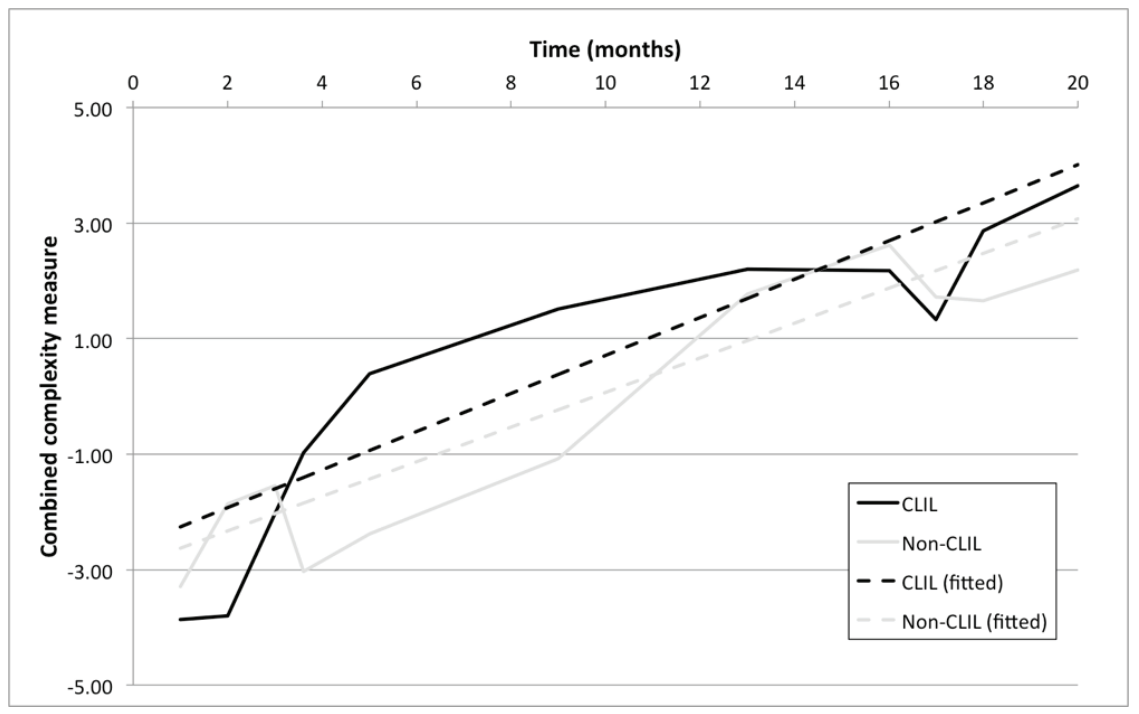

Figure 1: Observed means (solid lines) and fitted linear evolution (dashed lines) per group (combined measure).

(0.05). The differences between both groups are not significant, but the overall increase over time is. Looking at verb morphology, the CLIL group's intercept is estimated slightly higher (4.70) than the other group's (4.50). Its increase over time is also steeper (0.08) than for the non-CLIL group (0.06). The effect of time is significant, but the differences between both groups are not. Finally, the score on the combined measure at the onset of the study is higher for the CLIL $(-2.59)$ than for the non-CLIL group $(-2.93)$. The increase over the course of the study is slightly steeper for the CLIL group (0.33 vs 0.30 ), but this difference is not significant. The overall increase over time is significant, however. Figure 1 provides an illustration of how the group averages at each data point are linearly modelled for both groups for the combined complexity measure.

Overall, the results are remarkably consistent across outcome measures. In all cases, a significant increase in scores over the course of the study is found across both groups, but no significant difference is found between the two groups, either in terms of mean overall scores or in terms of estimated rate of increase over time.

\section{Discussion}

The first research question concerned the nature of the evolution of second language writing complexity over time in our data set. On average, the ten learners showed a clear increasing linear trend over the course of the study 
for each of the complexity measures used. This is in line with expectations. The participants in this study were beginning learners of L2-English in a secondary school context who received a considerable amount of formal EFL instruction (in addition to the extracurricular exposure to English they may have had). Previous studies have shown that periods of a couple of weeks or even months in instructional contexts may be too short to register significant changes in selected syntactic complexity measures (such as MLTU and SCR), but that a one-year observation period may suffice for substantial changes to emerge (Ortega 2003). The results of this study are in line with this observation. Also, measures of lexical diversity, and Guiraud's index in particular, have been found to increase significantly alongside overall L2 proficiency and development, given sufficiently large time intervals or differences in proficiency level (Bulté et al. 2008; Verspoor, Schmid and Xu 2012). Evidence of morphological complexity development is scarcer (Brezina and Pallotti 2019), and the observed increase over time is the least pronounced for the morphological complexity component in our analysis. This may be due to the small number of relevant morphological categories to be acquired in English, which offers only limited space for growth (De Clercq and Housen 2019). Finally, the fact that the scores on the combined measure significantly increase over the course of the study is not surprising considering the observed patterns for the individual measures.

With regard to the second research question, 'Are there differences in the rate and amount of L2 writing complexity development between CLIL and non-CLIL pupils?', we can be brief: no significant differences in L2 writing complexity development were found between the two groups of pupils. Such differences could be expected, especially in terms of rate of development, with the CLIL group gradually outperforming the non-CLIL group. But this is not the case here. This finding corroborates those of a few other (published) studies which also failed to demonstrate such differences in the domain of linguistic complexity in L2 writing in secondary school contexts (e.g. Pérez-Vidal and Roquet 2015). Moreover, this finding is also in line with the findings of other studies that suggested that CLIL learners do not improve more than non-CLIL learners in the use of certain grammatical aspects (e.g. inflectional morphology, word order, subordination), or at least not as much as they improve on measures of general L2 competence (Martínez Adrián and Gutiérrez Mangado 2015a, b; Ruiz de Zarobe 2010, 2011).

Nevertheless, this finding runs counter to the general and popular belief in the supremacy of CLIL education over regular, non-CLIL education for FL learning and attainment, a belief that has indeed found confirmation in the findings of the majority of CLIL effectiveness studies conducted so

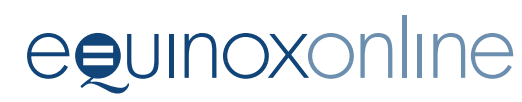


far, and which looked at aspects of L2 proficiency other than the complexity constructs investigated in our study (cf. the review in the first section of this paper). This finding is even more unexpected in light of the substantial differences in amount and type of classroom exposure to English between the two groups in our study, which clearly favour the CLIL pupils. In contrast to other studies that found no differences between CLIL and non-CLIL learners, where the difference between the two groups in terms of amount of classroom exposure was relatively small (e.g. Pérez-Vidal and Roquet 2015), the CLIL pupils in our study received seven and a half times more English at school than their non-CLIL counterparts through the combination of English content teaching plus EFL teaching (975 hours vs 130 hours). By the same token, one may also assume that the CLIL pupils in our study were not just exposed to more but also to more diverse and richer input (e.g. greater diversity and dispersion of lexical and grammatical types; see Madlener 2015), characteristics that one could expect to promote an increase in the CLIL pupils' lexical, morphological and syntactic diversity and other complexity-related constructs. But however richer and more diverse the linguistic input of the CLIL pupils in our study may have been, it did not result in greater improvement in terms of their linguistic L2 complexity development.

The lack of a clear CLIL effect on L2 complexity development in our study is also unexpected in light of the fact that in our study, as indeed in many other comparative CLIL studies, there is a selection bias favouring the CLIL pupils, who were selected and allowed into the CLIL programme on the basis of their motivation and perceived aptitude for foreign languages. ${ }^{5}$ But whatever advantage or head start the CLIL pupils in our study may have had, it did not manifest itself in terms of the complexity dimension of their written English proficiency, neither at the onset of our study (cf. Figure 2, which shows that the CLIL pupils actually scored lower on the combined complexity measure than the non-CLIL pupils, though not significantly so), nor in their ability to build on this advantage in terms of the complexification of their English writings in the course of the first nineteen months of the CLIL programme.

There are several possible reasons for the absence of a clear CLIL effect on L2 complexity development in our study. Some of these relate to the methodological limitations of our study. A first possible methodological explanation is that the CLIL classes in this study primarily fostered the development of specific (e.g. technical) language skills in the target language that are relevant to the subject matter in question, and that the complexity measures used in this study insufficiently tap into these linguistic skills (cf. Dalton-Puffer 2017, for a similar explanation). Further

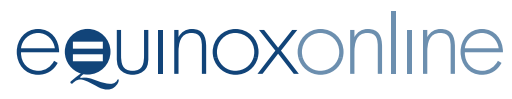


studies using different, more specific complexity measures (e.g. targeting infrequent lexis or grammatical constructions such as passives, relatives or conditionals) are needed to verify this explanation.

Second, it is also possible that whatever cumulative effect the CLIL experience on the L2 complexity development of our pupils may have had, it did not yet manifest itself in the nineteen months' duration of development tracked in our study. Only longitudinal studies with longer observation periods (and sufficiently dense data collection points) can shed light on this issue. Whatever the case with respect to the two aforementioned explanations may be, as 'absence of evidence is not evidence of absence' explanations for null-findings, they are clearly not scientifically attractive or theoretically interesting. A third, and theoretically more interesting, explanation may be that whatever benefits the additional and more varied exposure to English in the CLIL classes may have bestowed, they were ultimately outweighed or cancelled out by the even stronger impact of the substantial extracurricular, out-of-school exposure that both the CLIL and the non-CLIL pupils experienced (especially via the media; see Lindgren and Muñoz 2013; Sundqvist and Sylvén 2016; and Housen 2012, for similar explanations of similar findings from other multilingual and traditional FL programmes in contexts with ample extramural exposure to the target language). Further investigation of this hypothesis could proceed along two lines. First, through an examination of individual variation and variability in L2 complexity development and in the amount and type of extramural exposure to the CLIL language among the learners in the present sample (unfortunately, longitudinal information about individual learners' extramural exposure to English was not available). Second, through a comparison of the L2 complexity development of matched CLIL and non-CLIL learners in a context where ample extramural exposure to the TL is available vs a context where no or far less extramural exposure is available (while of course controlling for other potential determinants of L2 complexity development, including typological proximity between L1 and L2; e.g. comparing L2 complexity development in similar English CLIL programmes in the Netherlands vs in Germany, or selected parts of Quebec vs in France).

A final possible explanation may be related to the relatively young age of our learners (aged 11-13), their still ongoing cognitive maturation and the associated cognitive efforts and demands required by the writing tasks themselves (Olive 2012), all of which may have prevented both the CLIL and the non-CLIL pupils from writing texts of greater complexity, as their limited cognitive resources forced them to prioritise aspects of their task

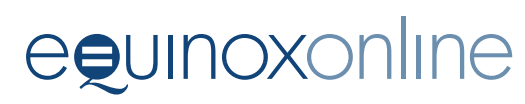


performance other than linguistic complexity (e.g. accuracy, task completion) (see e.g. Robinson 2001; Skehan 1998).

\section{Conclusion}

This exploratory study illustrated how beginning instructed second language learners in a secondary school English CLIL programme and in a mainstream secondary programme with only traditional EFL lessons gradually improve the overall linguistic complexity of their L 2 writing by investigating the development of ten Dutch-speaking learners of L2-English over the course of nineteen months using a mixed model approach. A strong overall rising trend was found for all six measures of syntactic, lexical and morphological complexity. However, we found no evidence of significant differences in terms of rate of developmental progress over time between the CLIL and the non-CLIL learners. Nor were significant overall group differences observed.

These results thus confirm the findings of a few other studies (Martínez Adrián and Gutiérrez Mangado 2015a, b; Ruiz de Zarobe 2010, 2011) that the benefits of CLIL found in general L2 proficiency do not necessarily or do not easily extend to the acquisition of specific linguistic features such as those captured by the construct of L2 linguistic complexity and as manifested in learners' L2 written productions. It goes without saying that our findings do not imply that the CLIL programme in our study (or CLIL education in general) is no more effective for promoting general L2 proficiency than the mainstream, foreign language teaching-only programme. This study only considered one particular aspect of the pupils' L2 performance, namely linguistic complexity as operationalised by means of six carefully chosen quantitative measures of syntactic, morphological and lexical complexity. It is possible that different effects would have been found for different complexity measures, or for other dimensions of L2 proficiency and development, such as accuracy and fluency, and there may have been trade-off effects between the different L2 proficiency dimensions.

More generally, we refrain from making strong claims about the effects and effectiveness of CLIL in fostering linguistic complexity in an L2 because of the limitations of the design and the analytical procedures used. Some of these limitations have already been addressed in the Discussion section. Additional limitations include the small sample size, especially in terms of number of learners $(n=10)$. This limits the generalisability of the results, and also restricts the possibilities in terms of modelling, especially given the large amount of variation inherent in the outcome measures. Second, with a general mixed-effects model, the main focus is on modelling group 
means, rather than on individual patterns of development. There is always the question as to whether the average group trend is representative for the actual development of individual learners. We deliberately did not focus on inter- and intra-individual variation in this paper because this is an issue that deserves proper attention and space. However, in another study we do explicitly analyse patterns of variation in the same data set examined here (Bulté and Housen 2018). Third, in the structure of our data set 'measurement occasion' coincided with 'prompt', making it hard to tease apart the effects of writing prompt and topic on the one hand, and time effects on the other (see Michel et al. 2019). Fourth, even though the quantitative measures used in this study were chosen to obtain a comprehensive yet parsimonious picture of L2 complexity, more and other complexity measures could be chosen that tap into different layers, components and dimensions of the linguistic complexity construct. A final limitation of our study (and indeed of many other longitudinal L2 development studies) is that the variable 'time' was used as a proxy for (amount of) 'L2 instruction and L2 contact', although it also runs parallel with the age of the participants, which is in turn linked to their cognitive development (Olive 2012). Since no first language writing samples were collected from the participants nor baseline data from native speaker peers, it is unclear to what extent the observed increase in complexity was due to the L2 development of the learners or to their general cognitive development.

To conclude, in our opinion this study illustrates how empirically investigating the impact of educational programmes such as CLIL on instructed second language acquisition is a necessary, fruitful and intriguing but also a challenging endeavour. Necessary, because judgments about the effects and effectiveness of instructional approaches must ultimately be based on solid empirical evidence. Fruitful and fascinating, because the study of CLIL (or other types of multilingual education) addresses fundamental issues in second language acquisition and teaching, and how they are affected by varying conditions. Challenging, because of the complex, multidimensional nature of both the instructional variables (such as CLIL education) and the outcome variables (such as linguistic complexity), the interacting effects of both learner-related, programme-related and contextual factors, and because of the multiple challenges - both conceptual and methodological - which they present.

\section{About the authors}

Bram Bulté has been a guest professor and post-doctoral researcher in linguistics at the universities of Brussels, Leuven and Ghent. He specialises in second language acquisition, statistics, computational linguistics and natural language processing.

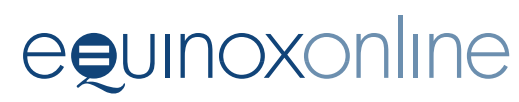


Alex Housen is Professor of English Linguistics and Applied Linguistics in the Department of Linguistics and Literary Studies at the Vrije Universiteit Brussel. His research focuses on linguistic, cognitive and social factors in second language acquisition, bilingualism, and bilingual and language education. His recent publications (in Studies in Second Language Acquisition, The Modern Language Journal and Second Language Research) deal with second language complexity and cognitive mechanisms in SLA.

\section{Notes}

1 Unless indicated otherwise, we use the term 'second language' (and its abbreviation 'L2') as a neutral cover term for any language that is not the learner's first language.

2 An increasing number of schools currently offer 'early English as a foreign language education' in the Netherlands, from as early as the first year of primary school onwards.

3 We use 'Foreign Language' (FL) and 'English as a Foreign Language' (EFL) here in the formal meaning of the terms to refer to any language in an educational context that is not the official language of instruction or of the society at large. See the section 'CLIL in the Netherlands' for a discussion of the status of English as a second or foreign language on the basis of its use and prevalence in Dutch society.

4 Although various tools are now available for automated complexity calculation (e.g. TAASSC, Kyle 2016; the Morpho-Complexity Tool, Brezina and Pallotti 2019), the reliability of these tools with early-stage learner language still needs to be further demonstrated. Therefore, preference was given to manual coding and calculation.

5 This selection bias is still a reality of many CLIL programmes in other countries as well (Dalton-Puffer 2011, 2017; Rumlich 2016).

\section{References}

Admiraal, W., Westhoff, G. and de Bot, K. (2006) Evaluation of bilingual secondary education in the Netherlands: students' language proficiency in English. Educational Research and Evaluation 12(1): 75-93. https://doi.org/10.1080/13803610500392160

Baerman, M., Brown, D. and Corbett, G.G. (eds) (2015) Understanding and Measuring Morphological Complexity. New York: Oxford University Press. https://doi. org/10.1093/acprof:oso/9780198723769.001.0001

Bardovi-Harlig, K. (1992) A second look at T-unit analysis: reconsidering the sentence. TESOL Quarterly 26(2): 390-5. https://doi.org/10.2307/3587016

Brezina, V. and Pallotti, G. (2019) Morphological complexity in written L2 texts. Second Language Research 35(1): 99-119. https://doi.org/10.1177/0267658316643125

Bruton, A. (2011) Is CLIL so beneficial, or just selective? Re-evaluating some of the research. System 39(4): 523-32. https://doi.org/10.1016/j.system.2011.08.002

Bruton, A. (2013) CLIL: some of the reasons why ... and why not. System 41: 587-97. https://doi.org/10.1016/j.system.2013.07.001

Bruton, A. (2017) Questions about CLIL which are unfortunately still not outdated: a reply to Pérez-Cañado (2017). Applied Linguistics Review. https://doi.org/10.1515/ applirev-2017-0059

Bulon, A., Hendrikx, I, Meunier, F. and Van Goethem, K. (2017) Using global complexity measures to assess second language proficiency. Comparing CLIL and non-CLIL learners of English and Dutch in French-speaking Belgium. Papers of the Linguistic 
Society of Belgium 11(1): 1-25.

Bulté, B. (2013) The development of complexity in second language acquisition. A dynamic systems approach. Unpublished doctoral dissertation. University of Brussels (VUB), Brussels.

Bulté, B. and Housen, A. (2012) Defining and operationalising L2 complexity. In A. Housen, F. Kuiken and I. Vedder (eds) Dimensions of L2 Performance and Proficiency. Investigating Complexity, Accuracy and Fluency in SLA 21-46. Amsterdam: John Benjamins. https://doi.org/10.1075/lllt.32.02bul

Bulté, B. and Housen, A. (2014) Conceptualizing and measuring short-term changes in L2 writing complexity. Journal of Second Language Writing 23(4): 21-45. https://doi. org/10.1016/j.jslw.2014.09.005

Bulté, B. and Housen, A. (2018) Syntactic complexity in L2 writing: Individual pathways and emerging group trends. International Journal of Applied Linguistics 28(1): 1-18. https://doi.org/10.1111/ijal.12196

Bulté, B., Housen, A., Pierrard, M. and Van Daele, S. (2008) Investigating lexical proficiency development over time - the case of Dutch-speaking learners of French in Brussels. Journal of French Language Studies 18: 277-98. https://doi.org/10.1017/ $\underline{\mathrm{s} 0959269508003451}$

Cenoz, J., Genesee, F. and Gorter, D. (2014) Critical Analysis of CLIL: taking stock and looking forward. Applied Linguistics 35(3): 243-62. https://doi.org/10.1093/applin/ amt011

Coyle, D., Hood, P. and Marsh, D. (2010) CLIL. Content and Language Integrated Learning. Cambridge: Cambridge University Press.

Dalton-Puffer, C. (2011) Content-and-language integrated learning: from practice to principles? Annual Review of Applied Linguistics 31: 182-204. https://doi. org/10.1017/S0267190511000092

Dalton-Puffer, C. (2017) CLIL in Practice - What does the Research Tell Us? Web publication, Goethe Institute. https:/www.goethe.de/en/spr/unt/kum/clg/20984546. html

Dalton-Puffer, C., Nikula, T. and Smit, U. (eds) (2010) Language Use and Language Learning in CLIL Classrooms. Amsterdam: John Benjamins. https://doi.org/10.1075/ aals.7

De Clercq, B. and Housen, A. (2019) The development of morphological complexity: A cross-linguistic study of L2 French and English. Second Language Research 35(1): 71-98. https://doi.org/10.1177/0267658316674506

Edwards, A. (2014) The progressive aspect in the Netherlands and the ESL/EFL continuum. World Englishes 33: 173-94. https://doi.org/10.1111/weng.12080

Gené-Gil, M., Juan-Garau, M. and Salazar-Noguera, J. (2015) Development of EFL writing over three years in secondary education: CLIL and non-CLIL settings. Language Learning Journal 43(3): 286-303. https://doi.org/10.1080/09571736.2015.105 3278

Guiraud, P. (1959). Problèmes et méthodes de la statistique linguistique. Dordrecht: Reidel.

Heatley, A., Nation, P. and Coxhead, A. (2002) RANGE and FREQUENCY programs. Retrieved on 18 January 2018 from http://www.victoria.ac.nz/lals/staff/paul-nation/ nation.aspx.

Housen, A. (2012) Time and amount of L2 contact inside and outside the school: Insights from the European schools. In C. Muñoz (ed.) Intensive Exposure Experi- 
ences in Second Language Learning 111-40. Clevedon, UK: Multilingual Matters. https://doi.org/10.21832/9781847698063-009

Housen, A. and Kuiken, F. (2009) Complexity, accuracy, and fluency in second language acquisition. Applied linguistics 30(4): 461-73. https://doi.org/10.1093/applin/ amp048

Housen, A., Schoonjans, E., Janssens, S., Welcomme, A. and Pierrard, M. (2011) Conceptualizing and measuring the impact of contextual factors in instructed SLA - The role of language prominence. International Review of Applied Linguistics in Language Teaching 49(2): 83-112. https://doi.org/10.1515/iral.2011.005

Jarvis, S. (2013) Capturing the diversity in lexical diversity. Language Learning 63(s1): 87-106. https://doi.org/10.1111/j.1467-9922.2012.00739.x

Jenniskens, T., Leest, B., Wolbers, M., Krikhaar, E., Teunissen, C., de Graaff, R., Unsworth, S. and Coppens, K. M. (2018) Evaluatie pilot tweetalig primair onderwijs: vervolgmeting schooljaar 2016/17. Report. Retrieved 15 April 2018 from https:// dspace.library.uu.nl/handle/1874/376282.

Kyle, K. (2016) Measuring syntactic development in L2 writing: fine grained indices of syntactic complexity and usage-based indices of syntactic sophistication. Doctoral dissertation. Retrieved 22 February 2018 from http://scholarworks.gsu.edu/alesl_diss/35.

Lahuerta Martínez, A. C. (2015) The written competence of Spanish secondary education students in bilingual and non-bilingual programs. Porta Linguarium 24: 47-61.

Lázaro, A. and García Mayo, M. (2012) L1 use and morphosyntactic development in the oral production of EFL learners in a CLIL context. International Review of Applied Linguistics in Language Teaching 50(2): 135-60.

Lindgren, E. and Muñoz, C. (2013) The influence of exposure, parents, and linguistic distance on young European learners' foreign language comprehension. International Journal of Multilingualism 10: 105-29. https://doi.org/10.1080/14790718.201 2.679275

Long, M. H. (1991) Focus on form: a design feature in language teaching methodology. In K. de Bot, R. B. Ginsberg and C. Kramsch (eds) Foreign Language Research in Cross-cultural Perspective 39-52. Amsterdam: John Benjamins. https://doi. org/10.1075/sibil.2.07lon

Lorenzo, F., Moore, P. and Casal, S. (2011) On complexity in bilingual research: the causes, effects, and breadth of content and language integrated learning - a reply to Bruton (2011). Applied Linguistics 32(4): 450-5. https://doi.org/10.1093/applin/ amr025

MacWhinney, B. (2000) The CHILDES Project: Tools for Analyzing Talk. Hillsdale, NJ: Lawrence Erlbaum.

Madlener, K. (2015) Frequency Effects in Instructed Second Language Acquisition. Berlin: de Gruyter. https://doi.org/10.1515/9783110405538

Malvern, D., Richards, B. J., Chipere, N. and Durán, P. (2004) Lexical Diversity and Language Development. New York: Palgrave Macmillan. https://doi. org/10.1057/9780230511804

Martínez Adrián, M. and Gutiérrez Mangado, M. (2015a) Is CLIL instruction beneficial in terms of general proficiency and specific areas of grammar? Journal of Immersion and Content-Based Language Education 31(1): 51-76. https://doi.org/10.1075/ jicb.3.1.03adr

Martínez Adrián, M. and Gutiérrez Mangado, M. (2015b) L1 use, lexical richness, accuracy and syntactic complexity in the oral production of CLIL and NON-CLIL learn- 
ers of English. Atlantis. Journal of the Spanish Association for Anglo-American Studies 37(2): 177-99.

McCarthy, P. and Jarvis, S. (2010) MTLD, vocd-D, and HD-D: a validation study of sophisticated approaches to lexical diversity assessment. Behavior Research Methods 42(2): 381-92. https://doi.org/10.3758/BRM.42.2.381

Michel, M., Murakami, A., Alexopolou, T. and Meurers, D. (2019) Effects of task type on morphosyntactic complexity across proficiency: evidence from a large learner corpus of A1 to C2 writings. Instructed Second Language Acquisition 3(2): 124-52.

Norris, J. M. and Ortega, L. (2009) Towards an organic approach to investigating CAF in instructed SLA: the case of complexity. Applied Linguistics 30(4): 555-78. https:// doi.org/10.1093/applin/amp044

Olive, T. (2012) Working memory in writing. In V. Berninger (ed.). Past, Present, and Future Contributions of Cognitive Writing Research to Cognitive Psychology 485503. New York: Psychology Press.

Ortega, L. (2003) Syntactic complexity measures and their relationship to L2 proficiency: a research synthesis of college-level L2 writing. Applied Linguistics 24(4): 492-518. https://doi.org/10.1093/applin/24.4.492

Pallotti, G. (2015) A simple view of linguistic complexity. Second Language Research 31(1): 117-34. https://doi.org/10.1177/0267658314536435

Pérez-Cañado, M. L. (2012) CLIL research in Europe: past, present, and future. International Journal of Bilingual Education and Bilingualism 15(3): 315-41. https://doi. org/10.1080/13670050.2011.630064

Pérez-Cañado, M. L. (2017) Stopping the 'pendulum effect' in CLIL research: finding the balance between Pollyanna and Scrooge. Applied Linguistics Review 8(1): 79-99. https://doi.org/10.1515/applirev-2016-2001

Pérez-Vidal, C. and Roquet, H. (2015) The linguistic impact of a CLIL science programme: an analysis measuring relative gains. System 54: 80-90. https://doi. org/10.1016/j.system.2015.05.004

Rescher, N. (1998) Complexity: A Philosophical Overview. London: Transaction Publishers.

Robinson, P. (2001) Task complexity, cognitive resources, and syllabus design: a triadic framework for examining task influences on SLA. In P. Robinson (ed.) Cognition and Second Language Instruction (pp. 287-318). Cambridge: Cambridge University Press. https://doi.org/10.1017/CBO9781139524780.012

Robinson, P. (2007) Criteria for grading and sequencing pedagogic tasks. In M.P. Garcia Mayo (ed.). Investigating Tasks in Formal Language Learning 7-27. Clevedon: Multilingual Matters. https://doi.org/10.21832/9781853599286-004

Ruiz de Zarobe, Y. (2010) Written production and CLIL: an empirical study. In C. Dalton-Puffer, T. Nikula and U. Smit (eds) Language Use and Language Learning in CLIL Classrooms 191-210. Amsterdam: John Benjamins. https://doi.org/10.1075/ aals.7.10rui

Ruiz de Zarobe, Y. (2011) Which language competencies benefit from CLIL? An insight into applied linguistics research. In Y. Ruiz de Zarobe, J. M. Sierra and F. Gallardo del Puerto (eds) Content and Foreign Language Learning. Contributions to Multilingualism in European Contexts 129-53. Bern: Peter Lang. https://doi. org/10.3726/978-3-0351-0171-3

Rumlich, D. (2016) Evaluating Bilingual Education in Germany: CLIL Students' General English Proficiency, EFL Self-concept and Interest. Frankfurt: Peter Lang. 
Schmidt, R. (1990) The role of consciousness in second language learning. Applied Linguistics 11(2): 129-58. https://doi.org/10.1093/applin/I.2.129

Skehan, P. (1998) A Cognitive Approach to Language Learning. Oxford: Oxford University Press. https://doi.org/10.1177/003368829802900209

Spada, N. (1997) Form-focused instruction and second language acquisition: a review of classroom and laboratory research. Language Teaching 30: 73-87. https://doi. org/10.1017/S0261444800012799

Sundqvist, P. and Sylvén, L. K. (2016) Extramural English in Teaching and Learning: From Theory and Research to Practice. London: Palgrave Macmillan. https://doi. org/10.1057/978-1-137-46048-6

Tomasello, M. (2003) Constructing a Language: A Usage-based Theory of Language Acquisition. Cambridge, MA: Harvard University Press.

Verbeke, G. and Molenberghs, G. (2000) Linear Mixed Models for Longitudinal Data. New York: Springer. https://doi.org/10.1007/978-1-4419-0300-6

Verspoor, M., de Bot, K. and Xu, X. (2015) The effects of English bilingual education in the Netherlands. Journal of Immersion and Content-Based Language Education 3(1): 4-27. https://doi.org/10.1075/jicb.3.1.01ver

Verspoor, M., Schmid, M. and Xu, X. (2012) A dynamic usage based perspective on L2 writing. Journal of Second Language Writing 21(3): 239-63. https://doi.org/10.1016/j. jslw.2012.03.007

Verspoor, M., Schuitemaker-King, J., Van Rein, E., De Bot, K. and Edelenbos, P. (2010) Tweetalig onderwijs: vormgeving en prestaties. Report. Retrieved on 20 February 2018 from https://www.nuffic.nl/documents/220/tweetalig-onderwijs-vormgevingen-prestaties.pdf

Wolfe-Quintero, K., Inagaki, S. and Kim, H.-Y. (1998) Second Language Development in Writing: Measures of Fluency, Accuracy, and Complexity. Honolulu: University of Hawaii, Second Language Teaching and Curriculum Center. 


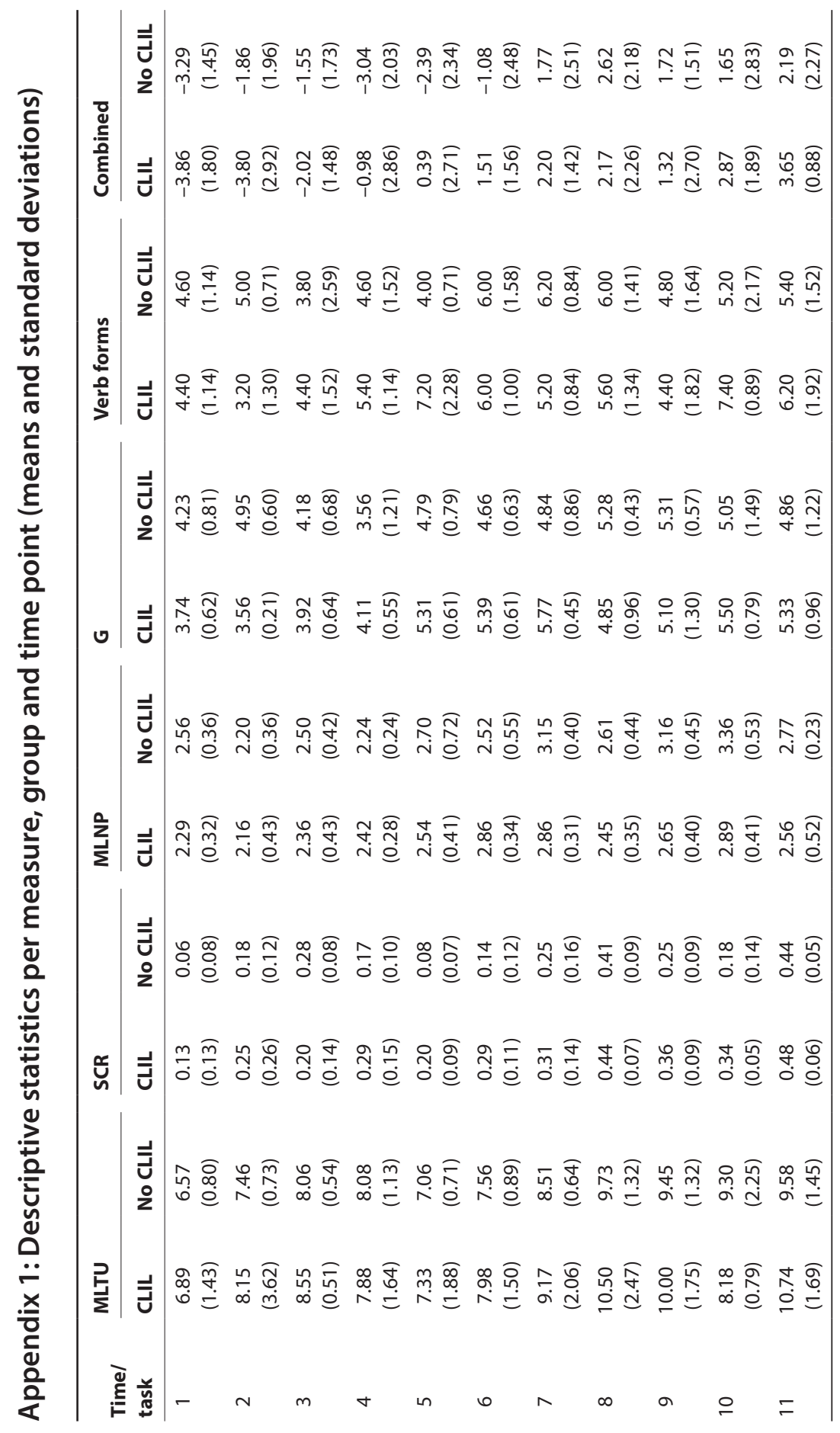

